\title{
Break the vicious cycle: Time for mentorship
}

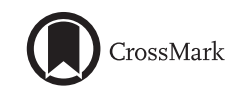

\author{
Ehud Raanani, MD
}

\footnotetext{
From the Division of Surgery, Department of Cardiac Surgery, and the Leviev Cardiothoracic and Vascular Center, Sheba Medical Center, Tel Hashomer, Israel.

Disclosures: Author has nothing to disclose with regard to commercial support.

Received for publication June 22, 2017; accepted for publication July 6, 2017; available ahead of print Aug 3, 2017.

Address for reprints: Ehud Raanani, MD, Sackler Faculty of Medicine, Tel Aviv University, Ramat Aviv, Tel Aviv 69978, Israel (E-mail: ehud.raanani@sheba.health.gov.il).

J Thorac Cardiovasc Surg 2017;154:1686

$0022-5223 / \$ 36.00$

Copyright $(\underset{2017}{ } 20 y$ The American Association for Thoracic Surgery

http://dx.doi.org/10.1016/j.jtcvs.2017.07.003
}

On reading the review in this issue of the Journal by Maron and coauthors, ${ }^{1}$ it became even more obvious to me most patients worldwide with hypertrophic obstructive cardiomyopathy do not receive optimal treatment. Patients are either kept on medical therapy (despite symptoms), referred for a less-effective intervention (alcohol septal ablation), or undergo suboptimal and unnecessary dangerous (as great as $6 \%$ mortality!) septal myectomies by surgeons who are not experienced in this field.

One of the problems is the misconception that septal myectomy is a very simple procedure: excise a piece of septal muscle from the left ventricular outflow tract and reduce obstruction. Because the surgical procedure seems very straightforward and not complex to the average surgeon, many times surgeons are tempted to perform it ad hoc. Although this procedure is neither complicated nor risky, surgeons do need to have learned a few careful steps regarding the surgical procedure, as well as knowing the precise anatomic indications that must often be tailored to the individual, to assess whether the patient will indeed benefit from a myectomy operation.

This causes a vicious cycle. Patients receive suboptimal surgery, clinical results are negative, there are fewer referrals by cardiologists to surgery, the surgical experience is further reduced, outcomes deteriorate, and so the cycle continues. The only way to break this vicious cycle is to create a worldwide network of mentors who will define the appropriate centers where there is a solid team composed of hypertrophic obstructive cardiomyopathy cardiologists and interested cardiac surgeons.

My personal experience is a perfect example. I underwent such training by one of the coauthors of this review (H.V.S.), ${ }^{1}$ who was prepared to visit our center and impart his expertise. As an experienced surgeon, my mentorship included observing and assisting in 7 surgical cases and then operating on 10 cases by myself with my mentor as an assistant. Surgical cases were collected to include a few septal myectomy procedures, which would coincide with each visit of the mentor. These visits included a thor-

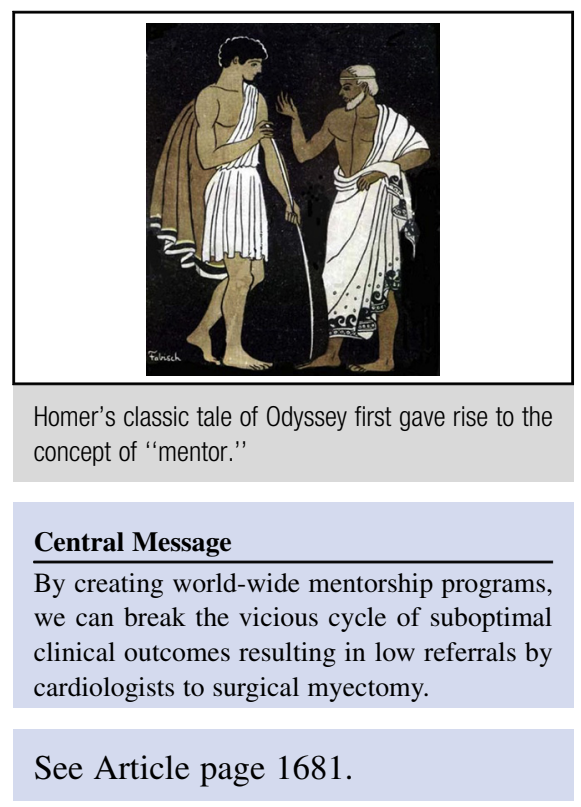

ough evaluation of all patients' imaging studies (mainly echocardiography and magnetic resonance imaging) in concert with our center's cardiologists (echocardiographers and heart failure and cardiomyopathy specialists), who then reviewed other cases of patients with hypertrophy, some of whom were considered unsuitable for surgery. In addition, the mentor delivered several overview lectures to all our center's cardiologists, radiologists, and cardiac surgeons.

This process provided me with the relevant experience to turn our department into a nationwide (population 8 million) surgical myectomy center, where more than 120 septal myectomy interventions have been performed in the last 7 years, with less than 1\% mortality and good clinical outcomes. This ongoing process gradually increases referrals to surgery and reduces the incentive of cardiologists to refer patients for unnecessary alcohol septal ablation ventures.

This type of mentorship can be performed on a personal basis. Even better, it can be sponsored and promoted by professional organizations (The American Association for Thoracic Surgery, Society of Thoracic Surgeons, European Association for Cardio-Thoracic Surgery).

\section{Reference}

1. Maron BJ, Dearani JA, Maron MS, Ommen SR, Rastegar H, Nishimura RA, et al. Why we need more septal myectomy surgeons: an emerging recognition. J Thorac Cardiovasc Surg. 2017;154:1681-5. 